\title{
PROTECCIÓN DEL PATRIMONIO TURÍSTICO MEDIO AMBIENTAL EN CHILE. SISTEMA VIGENTE Y PRINCIPALES FALENCIAS A SUPERAR.
}

\section{PROTECTION OF THE ENVIRONMENTAL TOURIST HERITAGE IN CHILE. CURRENT SYSTEM AND DEFICIENCIES TO OVERCOME.}

\author{
ALEJANDRO ÁLVAREZ ARAVENA ${ }^{1}$ \\ Abogado, Licenciado en Ciencias Jurídicas y Sociales de la Universidad Finis Terrae \\ Licenciado en Teología de la Pontificia Universidad Católica de Chile \\ Académico de Derecho Privado \\ MAXIMILIANO OLIVARES RAMÍREZ . \\ Abogado, Licenciado en Ciencias Jurídicas Universidad de Talca.
}

\section{Resumen}

Este trabajo tiene por objetivo dar cuenta de los principales instrumentos contenidos en la legislación chilena para proteger el patrimonio turístico, revisando las sanciones que se imponen ante la infracción de las obligaciones que pesan sobre los turistas. Junto con ello y a raíz de casos emblemáticos que han afectado al país, se pretende determinar la forma en que la legislación debe adaptarse para afrontar los desafíos que una actividad en crecimiento plantea a nuestro entorno.

Palabras Claves: Patrimonio turístico, daño ambiental, legislación chilena.

\section{Abstract}

This work aims to give an account of the main instruments present in the Chilean legislation which protect the touristic heritage, by reviewing the sanctions imposed in tourists due to the possible infringement of their obligations. Along with this, and as a result of some emblematic cases that have affected the country, it is intended to determine the way in which the legislation should adapt to face up the challenges raised by a growing activity to our environment.

Key Words: Touristic heritage, environmental damage, Chilean legislation.

Fecha de recepción: 18 de noviembre de 2018 Fecha de aprobación: 21 de febrero de 2019

\section{INTRODUCCIÓN}

La actividad turística en Chile ha experimentado un crecimiento exponencial durante los últimos diez años, convirtiéndose en uno de los ejes centrales de la economía de nuestro país. La existencia de políticas públicas destinadas a promover la actividad turística a lo largo de todo el territorio ha posicionado a Chile como uno de los países que recibe más turistas en América del Sur $^{3}$. Por otra parte, la creación de una institucionalidad especializada y enfocada específicamente al desarrollo del turismo con la publicación de la Ley 20.423 de 12 de febrero de 2010, marca un importante hito en el robustecimiento de esta actividad.

\footnotetext{
1 analvare@uc.cl

2 maxolivares@utalca.cl

${ }^{3}$ ORGANIZACIÓN MUNDIAL DEL TURISMO, Barómetro del Turismo mundial, 2018, volumen 16m marzo/abril 2018.
} 
Las cifras entregadas por la Subsecretaría de Turismo dan cuenta de la relevancia que ha adquirido a nivel nacional. Así, durante el período correspondiente al año 2017, la actividad turística se posiciona en el cuarto lugar de la exportación de bienes del país, luego de la minería, el sector frutícola y los productos químicos. Desde la perspectiva económica importa la generación de \$4.253 millones de dólares en el período estudiado.

En otro ámbito, el año 2017 significó el período en que se registró la mayor llegada de turistas desde los registros del año 2008. Así, se registró el ingreso de 6.449.000 de turistas provenientes principalmente de Argentina, Brasil, Estados Unidos, España, Francia, Alemania, y entre otros, Inglaterra. Del total de los de turistas que ingresaron al país, el 61,3\% de los viajes realizados tuvo como motivo vacacionar en Chile.

Finalmente, se cuenta con un dato relevante en cuanto al lugar en que se desarrolla esta actividad, ya que 3.019.432 personas visitaron las Áreas Silvestres Protegidas del Estado, destacando las visitas al Parque Nacional Vicente Pérez Rosales, la Reserva Nacional Los Flamencos y el Parque Nacional Torres del Paine como los tres más concurridos respectivamente.

Los datos aportados parecen ser muy positivos, pero este aumento progresivo y constante en el desarrollo de la actividad turística plantea diversos desafíos para la protección patrimonio turístico tanto natural como artificial. El incremento de visitas turísticas aumenta también el riesgo de que se produzcan consecuencias negativas o desfavorables en lugares visitados, fenómeno del cual Chile no es ajeno, ya que ha debido soportar la destrucción de parte importante de su patrimonio ante descuidos e imprudencias de quienes desarrollan la actividad turística.

De tal modo, es pertinente analizar la legislación actual para determinar los mecanismos que protegen el patrimonio turístico desde todas las aristas del ordenamiento jurídico, para poder evaluar si se encuentra a la altura de los datos que año a año demuestran una creciente actividad turística, a la orden de otorgar protección al patrimonio turístico. Con ello, la existencia de casos emblemáticos que han sobrepasado nuestra legislación y causado daños considerables al patrimonio turístico deben ser tomados como valiosas lecciones para proyectar mejoras a un sistema que tiene desafíos latentes debido al atractivo que se ha generado en el territorio chileno.

\section{PROTECCIÓN DEL PATRIMONIO TURÍSTICO}

La legislación chilena establece distintos instrumentos que tienen como objetivo directo o indirecto proteger el patrimonio turístico, que según lo establecido en el artículo quinto letra d de la Ley 20.423 se entiende por: "conjunto de bienes materiales e inmateriales que pueden utilizarse para satisfacer la demanda turística.” Dicha definición es lo suficientemente amplia como para otorgar protección a la totalidad de los atractivos turísticos que puedan existir, pero tal amplitud también puede ser problemática al no circunscribir de manera más específica su alcance. Sin perjuicio de este aparente problema, creemos que la decisión legislativa es correcta puesto que posee la flexibilidad necesaria para adaptarse a los nuevos potenciales turísticos que puedan generarse conforme a la demanda de visitas o interacciones.

A través de una legislación inorgánica y no centralizada en un cuerpo normativo único, se ha otorgado protección a este patrimonio mediante sanciones a quienes generen daños. Como se menciona, el ordenamiento jurídico turístico se ve complementado por otras normas y en especial la Ley número 19.300 Sobre Bases Generales del Medio Ambiente la que se encarga de dar contenido al concepto de patrimonio turístico material del tipo natural, que se conceptualiza en el artículo segundo letra b de la citada ley como: "el uso y aprovechamiento racionales o la reparación, en su caso, de los componentes del medio ambiente, especialmente aquellos propios del país que sean únicos, escasos o representativos, con el objeto de asegurar su permanencia y su capacidad de regeneración"

\section{1.- Derecho Civil}

La protección que en mayor parte entrega el Derecho Civil a los bienes jurídicos relevantes tiene como regla general la procedencia de indemnización de todos los perjuicios que 
sean causados en el desarrollo de una actividad, bien sea de manera intencional o de manera culposa.

Las normas generales de nuestra legislación no contienen regulación específica respecto de la generación de daños al patrimonio turístico, debiendo al respecto estar a las consideraciones generales. De tal forma, y según lo dispuesto en el artículo 2314 del Código Civil: "El que ha cometido un delito o cuasidelito que ha inferido daño a otro, es obligado a la indemnización; sin perjuicio de la pena que le impongan las leyes por el delito o cuasidelito." La referida norma establece con claridad la obligación de indemnizar los daños producidos, conservando la posibilidad de que el autor sea sancionado conforme a otros estatutos especiales.

En los casos de responsabilidad civil extracontractual, se debe responder ante el incumplimiento de un deber general de cuidado con el que las personas deben guiar su actuar. La extensión del resarcimiento de los perjuicios se sujeta al principio de reparación integral del daño, que implica el resarcimiento de todos los perjuicios que la acción u omisión, dolosa o culpable puede haber causado.

Los requisitos para la procedencia de la acción indemnizatoria han sido sistematizados por la doctrina y reforzados por los pronunciamientos constantes de los tribunales de justicia, por lo que se entiende que: "Los requisitos de la responsabilidad civil por culpa o negligencia pueden ser ordenados en cuatro grupos: i) una acción libre de un sujeto capaz, ii) realizada con dolo o negligencia, iii) que el demandante haya sufrido un daño y iv) que entre la acción culpable y el daño exista una relación causal suficiente para que éste pueda ser objetivamente atribuido al hecho culpable del demandado." 4

Pero es en causas de responsabilidad extracontractual en que el patrimonio turístico que se ve afectado es de componente natural, donde encontramos un enlace con la legislación ambiental que establece algunos matices en la clásica comprensión de los perjuicios comunes.

En efecto, el concepto del daño causado recibe un tratamiento especial en atención a un criterio que se ha catalogado como de relevancia en este, en virtud del cual no todo daño sería indemnizable, sino solo aquel que revista las características de significancia en atención a la pérdida, disminución, detrimento o menoscabo del medio ambiente o de uno o más de sus componentes. De tal forma, el legislador ha impuesto un requisito de ingreso más alto que la regla general para acceder a una pretensión indemnizatoria ambiental. Este criterio tiene su fundamento en que no cualquier afectación al patrimonio ambiental puede generar la obligación, cuestión que compartimos parcialmente ya que en algunos casos puede significar un verdadero obstáculo adicional para las víctimas del daño.

Por otra parte, se establece la posibilidad de que la víctima no esté individualizada como en los conceptos clásicos de responsabilidad civil suele ser. Se introduce así la concepción de interés colectivo, en virtud del cual una comunidad que en su totalidad ha sido perjudicada puede accionar, sumando se alguna forma la afectación que de la que cada integrante ha sido víctima para dotar a la acción de la gravedad que se requiera.

Fuera de aquellas modificaciones, todo lo demás se sujeta a las reglas generales del derecho común, generando así dificultades propias de un procedimiento de aplicación general ${ }^{5}$ como lo es la existencia de dificultades probatorias, largos tiempos de resolución y ejecución de

${ }^{4}$ BARROS ENRIQUE, Tratado de responsabilidad extracontractual. Santiago, Editorial Jurídica de Chile, pp. 61-62.

${ }^{5}$ A modo ejemplar, podemos citar la sentencia de Corte Suprema rol número 7467-2013 de 24 de junio de 2014, que en su considerando duodécimo establece que: "Que por otro lado, cabe precisar que habiéndose acreditado que los malos olores percibidos en los sectores aledaños a la planta de tratamiento de aguas servidas La Farfana, en diciembre de 2003 y octubre de 2004, se produjeron por culpa de la demandada, en razón de su actuar negligente en la operación de dicha planta, por la sobrecarga de los digestores y el no retiro oportuno de los lodos de la cancha de secado, resultan irrelevantes las argumentaciones de los demandantes referidas al grado de culpa del que respondería la demandada, por cuanto no cabe hablar de graduación de la culpa cuasidelictual o aquiliana" Lo que demuestra que por estar regido por las reglas de la responsabilidad extracontractual no se modifica la culpa aun cuando se demuestre una mayor negligencia. 
las sentencias, entre otros problemas relacionados con la alta especialización que requieren estos juicios tanto de las alegaciones de las partes como del conocimiento del juzgador. ${ }^{6}$

\section{2.- Derecho Penal}

El Derecho Penal como sanción de ultima ratio contempla supuestos de hecho que tienen como bien jurídico protegido el medio ambiente que en virtud de las definiciones ya analizadas pueden constituir patrimonio turístico y por consiguiente ser parte del presente análisis. Cabe destacar que no existe en nuestra legislación una sanción al ilícito ambiental o turístico. De tal forma, la doctrina ha señalado a este respecto que: "Como resulta evidente de la presentación de las diversas mociones parlamentarias surgidas en la materia, no existe en Chile una protección penal sistemática y enfocada precisamente a la protección del medio ambiente en sí, como no existía en la mayor parte de las legislaciones del siglo pasado, básicamente porque al consolidarse la codificación decimonónica, no había una preocupación por el medio ambiente como tal como hemos visto hay hoy en día."7

De tal forma, las normas que analizaremos son las que castigan la afectación de algunos de los elementos del medio ambiente, que según la definición contemplada en el artículo 2 letra ll de la Ley Sobre Bases Generales del Medio Ambiente corresponde a: "el sistema global constituido por elementos naturales y artificiales de naturaleza física, química o biológica, socioculturales y sus interacciones, en permanente modificación por la acción humana o natural y que rige y condiciona la existencia y desarrollo de la vida en sus múltiples manifestaciones."

Así, la intervención de esta rama del Derecho con el fin último de proteger el medio ambiente se encuentra limitada a determinados aspectos que dicen relación con conductas desplegadas por las personas y que se traducen en la producción de un daño al componente ambiental. A continuación, analizaremos las principales sanciones existentes al respecto.

En primer término, encontramos la Ley de Bosques que sanciona el corte o destrucción de árboles y arbustos en contravención a sus disposiciones con la pena de presidio menor en su grado mínimo (nota al pie lo que implica privación de libertad desde 61 a 540 días) y, junto con ello, una multa que parte en los diez sueldos vitales mínimos teniendo como tope los veinte sueldos vitales mínimos. ${ }^{8}$

Lo particular de esta norma es que no representa una prohibición absoluta a la tala de este tipo de recurso natural, sino que establece en su artículo quinto la regulación de ello: "Se prohíbe: $1^{\circ}$ La corta de árboles y arbustos nativos situados a menos de 400 metros sobre los manantiales que nazcan en los cerros y los situados a menos de 200 metros de sus orillas desde el punto en que la vertiente tenga origen hasta aquel en que llegue al plan; $2^{\circ}$ La corta o destrucción del arbolado situado a menos de 200 metros de radio de los manantiales que nazcan en terrenos planos no regados; y $3^{\circ}$ La corta o explotación de árboles y arbustos nativos situados en pendientes superiores a 45\%. No obstante, se podrá cortar en dichos sectores sólo por causas justificadas y previa aprobación de plan de manejo en conformidad al decreto ley $N^{\circ} 701$, de 1974.”

Así, observamos que los parámetros generados por esta Ley tienen que ver con la calidad de árbol o arbusto nativo que tenga la especie sujeta a la acción de tala o destrucción y un carácter métrico respecto de la ubicación en que éstos se encuentran, limitando así el espectro de

${ }^{6}$ Puede resultar muy interesante para comprender el sistema administrativo chileno el trabajo de: GUERRRA SCHLEEF, FELIPE, Redundancia jurisdiccional como estrategia en ámbitos conflictivos del contenciosoadministrativo en Chile, en: Revista de Derecho Universidad Austral de Chile, Vol. XXX ํำ-Junio 2017, Paginas 153-177.

7 MATUS ACUÑA, ORELLANA CRUZ, CASTILLO SÁNCHEZ y RAMÍREZ GUZMÁN, Análisis dogmático del derecho penal ambiental chileno, a la luz del derecho comparado y las obligaciones contraídas por chile en el ámbito del derecho internacional. Conclusiones y propuesta legislativa fundada para una nueva protección penal del medio ambiente en Chile, en: Revista Ius et Praxis, 2003, año 9 №2. Pp. 11-57.

\footnotetext{
${ }^{8}$ Corresponde aproximadamente a 4.187 dólares en el mínimo y a 8.374 dólares en su máximo.
} 
protección normativo de estas especies excluyendo evidentemente las que no se encuentren en dicha hipótesis.

En segundo término, es relevante comentar las disposiciones de la Ley de Monumentos Nacionales dada la relevancia que ellos tienen como atractivo turístico en nuestro país. La Ley 17.288 publicada el 04 de febrero de 2018 define en su artículo primero lo que se entiende por monumentos nacionales en los siguientes términos: "Son monumentos nacionales y quedan bajo la tuición y protección del Estado, los lugares, ruinas, construcciones u objetos de carácter histórico o artístico; los enterratorios o cementerios u otros restos de los aborígenes, las piezas u objetos antropo-arqueológicos, paleontológicos o de formación natural, que existan bajo o sobre la superficie del territorio nacional o en la plataforma submarina de sus aguas jurisdiccionales y cuya conservación interesa a la historia, al arte o a la ciencia; los santuarios de la naturaleza; los monumentos, estatuas, columnas, pirámides, fuentes, placas, coronas, inscripciones y, en general, los objetos que estén destinados a permanecer en un sitio público, con carácter conmemorativo. Su tuición y protección se ejercerá por medio del Consejo de Monumentos Nacionales, en la forma que determina la presente ley."

La definición contemplada en la Ley especial citada establece de manera clara los lugares que se regulan por medio de estas normas, siendo los más destacados por su importancia turística Isla de Pascua, la Oficina Salitrera de Chacabuco, la Catedral de Santiago, la Plaza de Armas de Santiago, entre otros. Según la información del Consejo de Monumentos Nacionales de Chile, al 5 de noviembre de 2018 se encuentran declarados por decreto a nivel nacional 447 Monumentos Históricos Muebles, 1047 Monumentos Históricos Inmuebles, 55 Santuarios de la Naturaleza, 142 Zonas Típicas, siento en total $1691^{9}$ Monumentos Nacionales que reciben la protección de la referida norma.

La protección de estos monumentos desde el punto de vista punitivo se contiene en los artículos 38 y 38 bis de la ya mencionada Ley. El primero de ellos sanciona aquellos que causen daño a un monumento nacional o que afectan de cualquier modo su integridad. La norma no establece que el daño debe ser irreparable, por lo que se comprende dentro del supuesto sancionado cualquier tipo de afectación a estos bienes o su integridad, entregando una protección bastante amplia respecto de los daños que se podrían ocasionar. La sanción contemplada para este ilícito es la pena de presidio menor en sus grados medio ${ }^{10}$ a máximo ${ }^{11}$, y junto con ello multa de cincuenta a doscientas unidades tributarias mensuales. ${ }^{12}$

A su turno, el artículo 38 bis trata sobre los supuestos en que se apropia un bien nacional, consistiendo dicha apropiación constitutiva de alguno de los delitos de usurpación, hurto, robo con fuerza en las cosas, o robo con receptación. En este punto, cabe destacar que el tipo penal descrito por esta norma es más restringido, ya que debe referirse a un bien susceptible de ser objeto de tal acto, descartando así una aplicación extensiva de la norma. Las penas de este delito se disponen de manera especial y de manera general. La sanción especial dispuesta es una multa de cincuenta a doscientas unidades tributarias mensuales. ${ }^{13}$, y desde el punto de vista general, se realiza una remisión a los tipos penales generales mencionados. De tal forma, de modo ilustrativo, la pena asignada al delito de usurpación es meramente pecuniaria ${ }^{14}$, variando si existe o no violencia en las personas para consumarse.

Mención especial se realiza al hurto puesto que nuestra legislación establece un baremo de la pena en atención al valor del objeto que ha sido hurtado de tal manera, las sanciones son presidio menor en sus grados medio a máximo y multa de once a quince unidades tributarias

${ }^{9}$ CONSEJO DE MONUMENTOS NACIONALES DE CHILE, Estadística de Monumentos Nacionales declarados por decreto, 2018. [consulta: 09 de noviembre de 2018]. Disponible en: http://www.monumentos.cl/monumentos/

${ }^{10}$ Dicha pena corresponde a 541 días a 3 años de acuerdo al ordenamiento jurídico chileno.

${ }^{11}$ Dicha pena corresponde a 3 años y 1 día a 5 años de acuerdo al ordenamiento jurídico chileno.

${ }^{12}$ Corresponde a una multa entre 3.501 y a 14.004 dólares en su máximo.

${ }^{13}$ Ídem

${ }^{14}$ En caso de existir violencia corresponde a una multa entre 781 a 1420 dólares y en ausencia de violencia a una multa entre 426 a 710 dólares. 
mensuales cuando el valor de la cosa hurtada exceda las cuarenta unidades tributarias mensuales; con presidio menor en su grado medio y multa de seis a diez unidades tributarias mensuales, si el valor de la cosa es mayor a cuatro unidades tributarias mensuales y no superior a cuarenta unidades tributarias mensuales; con presidio menor en su grado mínimo y multa de cinco unidades tributarias mensuales si el valor de la cosa excede de media unidad tributaria mensual y no pasare de cuatro unidades tributarias mensuales y en caso de que la cosa que se ha hurtado tiene un valor superior a cuatrocientas unidades tributarias mensuales, se aplicará la pena de presidio menor en su grado máximo y multa de veintiuna a treinta unidades tributarias mensuales.

En todo caso, y como suele ser usual en estas situaciones, si no fuere posible determinar el valor del monumento nacional, se aplicará la pena de presidio menor en sus grados mínimo a máximo junto con la multa respectiva.

Finalmente, destacaremos otro componente protegido a través del derecho penal, que se encuentra regulado en la Ley General de Pesca y Acuicultura, Ley 18.892. En particular encontramos regulado en este cuerpo normativo la protección de los recursos hidrobiológicos, que se define en su artículo primero número 18: "Especies hidrobiológicas susceptibles de ser aprovechadas por el hombre." Complementado con el numeral 11: "especie de organismo en cualquier fase de su desarrollo, que tenga en el agua su medio normal o más frecuente de vida. También se las denomina con el nombre de especie o especies."

En particular, nos referiremos a una modificación introducida el 25 de octubre de 2008 dispuesta en el artículo 135 bis, que tipifica la matanza, actividades de caza o captura de un ejemplar de cualquier especie de cetáceos, será sancionado con la pena de presidio mayor en su grado mínimo y comiso de las especies. Además, se sanciona a quien tenga, posea, transporte, desembarque, efectúe cualquier proceso de transformación, así como comercialice o almacene estas especies vivas o muertas o parte, con la pena de comiso y presidio menor en su grado medio, incluyendo las sanciones administrativas que conforme a la ley procedan.

La regulación referente a los cetáceos se alinea con la prohibición total que en Chile rige respecto del comercio de estas especies, entregando una protección absoluta a un atractivo turístico que se encuentra presente en Arica, Caleta Chañaral de Aceituno y la Isla de Chiloé, por mencionar algunas.

\section{3.- Normas especiales:}

La legislación chilena ha contemplado normativa específica sobre el patrimonio turístico tendiente a establecer definiciones sobre la materia y proteger sus distintos componentes, analizaremos tres de las principales leyes.

\subsection{1.- Ley del Turismo 20.423.}

La ley chilena $\mathrm{N}^{\circ} 20.423$, denominada "Del sistema institucional para el desarrollo del turismo", promulgada el 4 de febrero del año 2010 y publicada el 12 de febrero del año 2010, por el ministerio de economía, fomento y reconstrucción, estableció como objeto el desarrollo y promoción de la actividad turística, a través de la creación, conservación y aprovechamiento de los recurso y atractivos turísticos nacionales.

Al mismo tiempo consagra el turismo como una actividad estratégica para el desarrollo, impulsando un crecimiento sustentable, como también una alianza público-privada, fomentando la asociatividad de los diversos actores de esta importante industria.

Sin lugar a dudas, uno de los principales aportes de este cuerpo normativo es la consagración de una Política Nacional del Turismo, así como la creación de una nueva institucionalidad que se expresa en: a) El Comité de Ministros; b) La Subsecretaría de Turismo; c) Las Zonas de Interés Turístico; d) El desarrollo Turístico en las Áreas Silvestres Protegidas por el Estado; e) El Consejo Consultivo de Promoción Turística; f) El Sistema de clasificación, calidad y seguridad de los Prestadores de Servicios Turísticos. 
Ahora bien, desde el punto de vista de la protección del patrimonio, la Ley del Turismo solo establece infracciones y sanciones que tienen por objeto la protección al turista, pero no al patrimonio, siendo competente para conocer de esas causas el Juzgado de Policía Local correspondiente al domicilio del prestador de servicios turísticos en que se detecte la infracción, y cuyo procedimiento se encuentra en la Ley $N^{\circ} 18.287$, publicada el 7 de febrero del año 1984, que establece procedimiento ante los Juzgados de Policía Local.

El desarrollo de la actividad turística es las Áreas Silvestres protegidas por el Estado, es una novedad de la ley en comento, toda vez que antes de la ley el turismo se encontraba absolutamente prohibido en estas Áreas. Así las cosas, el artículo 18 de la ley $N^{\circ} 20.423$ establece que solo se podrán desarrollar actividades turísticas, en tanto cuanto estas sean compatibles con el objeto de protección de las Áreas Silvestres Protegidas por el Estado, asegurando la diversidad biológica, la preservación de la naturaleza y la conservación del patrimonio ambiental.

Cada Área Silvestre Protegida por el Estado, debe contar con un plan de manejo, así como con un previo informe técnico de compatibilidad con este, y aprobado por el Comité de Ministros, para que un Área Silvestre Protegida sea intervenida o concesionada al sector privado, y por supuesto con la participación del Ministerio de Bienes Nacionales, cuyo procedimiento la ley entregó a un reglamento que se tradujo en el Decreto 50 del Ministerio de Economía, Fomento y Turismo en conjunto con el Ministerio de Bienes Nacionales, que aprobó el reglamento que fija procedimiento para otorgamiento de concesiones turísticas en áreas silvestres protegidas del Estado.

El decreto 50, en el artículo 31 establece obligaciones para el concesionario de servicios turísticos en un área Silvestre Protegida: a) Realizar y ejecutar el proyecto adjudicado en los plazos establecidos; b) Cumplir con el plan de manejo del área; c) Cumplir con las demás normas y regulaciones dictadas para la respectiva área, por la autoridad encargada de la Administración de las Áreas Silvestres Protegidas del Estado; d) Informar sobre el desarrollo de la concesión en los plazos señalados en el respectivo contrato concesional; e) Pagar la renta concesional, si correspondiere; f) Rendir caución para garantizar, tanto la seriedad de la oferta como el fiel cumplimiento del contrato de concesión, cuando así sea exigido en las Bases Administrativas o en los Términos de Referencia, según corresponda; g) Permitir las inspecciones, que en el uso de sus atribuciones realice la autoridad encargada de la administración de las Áreas Silvestres Protegidas del Estado; h) Obtener todos los permisos y autorizaciones que, conforme a la legislación vigente, sean necesarios para el desarrollo del proyecto, e i) Las demás que emanen del decreto ley $\mathrm{N}^{\circ} 1.939$ del año 1977, y las que se fijen en el contrato concesional.

Por su parte el artículo 32 del mismo decreto, establece las causales de extinción de la concesión, relativas al cumplimiento del plazo, el mutuo acuerdo, incumplimiento grave de las obligaciones del concesionario, o el incumplimiento grave de las demás normas y regulaciones dictadas por la autoridad, la imposibilidad de usar o gozar la concesión según su objeto, la cancelación de la personalidad jurídica del concesionario, y las demás causales que estipulen las Bases de Licitación o en el contrato concesional.

Consecuentemente la Ley $\mathrm{N}^{\circ} 20.423$ y el decreto 50, si bien no establecen sanciones, es posible advertir la consagración de ciertos principios rectores y protectores del patrimonio turístico, en el sentido de establecer límites al libre ejercicio de la actividad turística en Áreas Silvestres Protegidas del Estado.

\subsection{2.- Ley sobre Bases Generales del Medio Ambiente ${ }^{15}$ No $^{\circ} 19.300$ del año 1994}

El 9 de marzo de 1994 se publicó en el Diario Oficial de Chile la ley Nº19.300, sobre Bases Generales del Medio Ambiente, que consagra cuatro aspectos relevantes. Primero, definiciones legales, tales como: biodiversidad, medioambiente, conservación del patrimonio ambiental, preservación de la naturaleza, impacto ambiental y daño ambiental. Segundo, Instrumentos de gestión ambiental: Sistema de Evaluación de Impacto Ambiental, Declaración de

${ }^{15}$ SABAY y ONAINDIA, comprenden como medio ambiente "el conjunto de elementos naturales, artificiales o creados por el hombre, físicos, químicos y biológicos, que posibilitan la existencia, transformación y desarrollo de organismo vivos” NOGUEIRA (2008), p 632. 
Impacto Ambiental y Estudio de Impacto Ambiental. Tercero, La responsabilidad en materia ambiental, tanto civil, como responsabilidad por daño ambiental propiamente tal. Cuarto, La Institucionalidad Ambiental a través de la Comisión Nacional del Medio Ambiente, y la Comisión Regional del Medio Ambiente.

La innovación de esta ley se encuentra en la denominada responsabilidad por daño ambiental $^{16}$, que da lugar a la acción ambiental, en relación con el artículo 3 de las disposiciones generales, estableciendo que todo el que culposa o dolosamente cause daño al medio ambiente tiene la obligación de reparar e indemnizar, lo que se diferencia de la indemnización ordinaria por daños y perjuicios, la que se puede ejercer independientemente de acuerdo con las reglas del Código Civil chileno.

Para establecer que existe daño ambiental, es necesario determinar la entidad del perjuicio, labor que en el ordenamiento chileno realiza el juez pronunciándose sobre si el daño es significativo o no, a diferencia de lo que ocurre en la ley federal alemana. ${ }^{17}$

La Ley $\mathrm{N}^{\circ}$ 20.417, que modifica la Ley $\mathrm{N}^{\circ} 19.300$ sobre Bases Generales del Medio Ambiente, creó el Ministerio del Medio Ambiente, el Consejo de Ministros para la Sustentabilidad, el Servicio de Evaluación Ambiental y la Superintendencia del Medio Ambiente.

Desde el punto de vista de las sanciones, la Ley $\mathrm{N}^{\circ} 20.417$ aumenta significativamente las sanciones contempladas en la Ley $\mathrm{N}^{\circ}$ 19.300. Las nuevas sanciones incluyen la amonestación por escrito, multas entre 1 a 10.000 Unidades Tributarias Anuales, (aproximadamente US\$ 8.400.000), clausura de instalaciones, y revocación de la Resolución de Calificación Ambiental.

\subsection{3.- Ley $\mathrm{N}^{\circ} 20.600$ del año 2012}

Con fecha 28 de junio de 2012, se publicó en el Diario Oficial de Chile la Ley №20.600 que crea los Tribunales Ambientales, que son tribunales especializados, bajo la superintendencia directiva, correccional y económica de la Corte Suprema de Chile, tal y como establece el artículo $1^{\circ}$ de dicho cuerpo normativo.

Estos Tribunales Ambientales son órganos colegiados, que no solo lo integran abogados, sino que además especialistas de otras áreas. Así la ley establece que sean dos abogados y un licenciado en ciencias con especialización en medioambiente, lo que es uno de sus rasgos característicos, es decir, Tribunales de Integración Mixta, que en la experiencia chilena tiene como referente al Tribunal de Defensa de la Libre Competencia, de acuerdo al Decreto Ley №211 de 1973, en su artículo 6 establece que el Tribunal estará integrado por un abogado y cuatro profesionales universitarios expertos en materias de libre competencia, dos de los cuales deberán ser abogados y dos licenciados en ciencias económicas.

La competencia de estos tribunales especializados es exclusiva para conocer las controversias ambientales, y especialmente para conocer: a) demandas por daño ambiental; b) Reclamaciones por resoluciones de la Superintendencia del Medio Ambiente; c) Medidas provisionales, tales como: clausura de instalaciones, detención de funcionamiento y suspensión temporal de Resolución de Calificación Ambiental; d) Autorizar sanciones; e) Reclamaciones contra el Director Ejecutivo del Servicio de Evaluación Ambiental o del Comité de Ministros.

La creación de los Tribunales Ambientales es fruto de un acuerdo transversal que permitió el rediseño de la institucionalidad ambiental contenida en la ley $\mathrm{N}^{\circ} 20.417$ del año 2010, otorgando amplias facultades de fiscalización y sanciones. ${ }^{18}$ De este modo los Tribunales

${ }^{16}$ VALENZUELA RAFAEL, El derecho ambiental presente y pasado. En Santiago, Editorial jurídica, p 355

17 BERMUDEZ JORGE, Fundamentos del Derecho Ambiental. En Valparaíso, 2010, Ediciones Universitarias de Valparaíso, p 238.

${ }^{18}$ BERGAMINI KAY, IRARRAZABAL RICARDO Y OTROS, Fiscalización, sanción y control ambiental en Chile. Diagnóstico y propuestas para la Superintendencia del Medio Ambiente y tribunales ambientales. En https://politicaspublicas.uc.cl/wp-content/uploads/2018/03/CAP-VI-Propuestas-para-Chile-2017.pdf 
Ambientales vienen a completar la institucionalidad que comprendía el Ministerio del Medio Ambiente, el Servicio de Evaluación Ambiental y la Superintendencia del Medio Ambiente.

El numero de tribunales y su jurisdicción se encuentran establecidos en el articulo $5^{\circ}$ de la Ley 20.600, que crea tres Tribunales Ambientales en todo el país, con asiento en Antofagasta, Santiago y Valdivia: "Número de Tribunales y Jurisdicción. Créase un Tribunal Ambiental con asiento en cada una de las siguientes comunas del país, con la jurisdicción territorial que en cada caso se indica: a) Primer Tribunal Ambiental, con asiento en la comuna de Antofagasta, y con competencia territorial en las Regiones de Arica y Parinacota, de Tarapacá, de Antofagasta, de Atacama y de Coquimbo. b) Segundo Tribunal Ambiental, con asiento en la comuna de Santiago, y con competencia territorial en las regiones de Valparaíso, Metropolitana de Santiago, del Libertador General Bernardo O'Higgins y del Maule. c) Tercer Tribunal Ambiental, con asiento en la comuna de Valdivia, y con competencia territorial en las regiones de Ñuble, del Biobío, de La Araucanía, de Los Ríos, de Los Lagos, de Aysén del General Carlos Ibáñez del Campo, y de Magallanes y de la Antártica Chilena.”

Los Tribunales Ambientales entraron en funcionamiento progresivamente, el 4 de marzo de 2013 inició sus actividades el Tribunal Ambiental de Santiago, con competencia para conocer las causas en todo el territorio nacional hasta el 9 de diciembre de 2013, en que inició su funcionamiento el Tribunal Ambiental de Valdivia, y finalmente el 4 de septiembre de 2017, en que entró en funcionamiento el Tribunal Ambiental de Antofagasta.

El artículo 17 de la Ley $N^{\circ} 20.600$ señala las materias especializadas que los Tribunales Ambientales están llamados a conocer, entre otras: Demandas de reparación de daño ambiental, Reclamos contra decisiones de la Administración Pública, Pronunciamientos sobre consultas y solicitudes de las Superintendencia del Medio Ambiente y de los demás asuntos que señalen las leyes.

\section{CASOS DE DAÑOS AL PATRIMONIO TURÍSTICO CHILENO}

La experiencia nacional no ha estado exenta de casos que ponen a prueba la institucionalidad destinada a proteger los distintos elementos del patrimonio ambiental, generando aprendizajes a través de vivencias que producen daños a los componentes que además de tener una relevancia ambiental configuran un atractivo turístico. Para dar cuenta de ello, estudiaremos una reseña de dos situaciones en que se ha generado una afectación del patrimonio turístico

\subsection{Incendio Forestal de Torres del Paine}

El Parque Nacional Torres del Paine se encuentra ubicado en la Región de Magallanes y la Antártica chilena, en la Provincia de Última Esperanza, comuna de Torres del Paine. Según las cifras ya mencionadas corresponde a uno de los Parques Nacionales más visitados, constituyendo además de un atractivo protegido a nivel nacional, una Reserva de la Biosfera declarada por la Unesco. La superficie total del Parque corresponde a 227.298 hectáreas.

En diciembre del año 2011, ingresó al parque un turista extranjero que declaró su permanencia en el parque por el lapso de 10 días. El día 27 de diciembre se alertó a los guardaparques encargados de la existencia de humo en el sector llamado Lago Grey, que en virtud de la magnitud de este y por ser una zona de difícil acceso, se declaró ese mismo día alerta roja en el Parque.

Detectada la existencia del incendio, se presentaron las peores condiciones posibles con fuertes vientos, lo que implicó que se consumieran aproximadamente 2.500 hectáreas diarias durante la primera semana del incendio. El control del siniestro exigió una fuerte coordinación nacional y apoyo extranjero que involucró a cerca de 800 profesionales en distintas labores durante los periodos más críticos. La extinción total del fuego en todos los focos se produjo recién el 8 de marzo de 2012, consumiendo aproximadamente 16.000 hectáreas. 
El origen del incendio fue la negligencia del turista que visitó el Parque, quien encendió una fogata con papel higiénico, la cual se habría descontrolado generando las terribles consecuencias ya descritas.

Desde el punto de vista jurídico, la pena a la que se exponía el autor de los hechos correspondía de 41 a 61 días de presidio, en el evento de poder acreditarse un manejo imprudente del fuego. La arista penal quedó cerrada en virtud de una suspensión condicional del procedimiento entre la Fiscalía y el imputado por lo que no existió pronunciamiento de dicha judicatura. El acuerdo consistió en que se coordinaría una campaña para producir 50.000 plantas de bosque con el objetivo de reforestar el Parque Nacional Torres del Paine, debiendo además entregar en la audiencia de suspensión la suma de 6.941 dólares, sin asumir responsabilidad en los hechos.

La discusión jurídica tuvo lugar en el área civil, donde el Fisco de Chile demandó la reparación del daño ambiental causado y la correspondiente indemnización de perjuicios por la responsabilidad extracontractual que recaía sobre el turista que inició el incendio. Tal como se indicó en el apartado relativo al Derecho Civil, la acción indemnizatoria que se intentó se ajustaba a las normas generales que regulan la responsabilidad por el obrar negligente que en este caso se atribuyó al hecho de encender fuego en un lugar que se encontraba expresamente prohibido, conocido por del autor del daño a través de un folleto que se le entregó al hacer ingreso al parque, y que contenía la prohibición señalada.

Por su parte, la acción de reparación del daño ambiental se enmarca en la regulación que la nueva legislación ambiental incorpora al ordenamiento jurídico chileno, teniendo como principal objetivo la generación de acciones tendientes a restablecer el patrimonio ambiental al estado en que se encontraba.

El Tribunal de primera instancia determinó que el turista era responsable del daño ambiental pero no de la indemnización de perjuicios por responsabilidad extracontractual, por lo que ambas partes involucradas en el litigio apelaron a la sentencia. La Corte de Apelaciones de Santiago confirmó el fallo de primera instancia, manteniendo la obligación de reparar el daño ambiental declarando además que el Estado de Chile puede exigir a un tercero la ejecución de las prestaciones condenadas en caso de que el turista no pueda hacerlo. Dentro de las prestaciones a que fue condenado se encuentran ejecutar una línea de base ambiental para medir los impactos causados luego del incendio, reparar el suelo, hábitat de la distintas especies de avifauna y el bosque nativo afectado con la catástrofe y la elaboración de planes bianuales de seguimiento ambiental con el objeto de dar cuenta del avance en la recuperación de los elementos que se han afectado en el medio ambiente del Parque Nacional, por un tiempo que no puede ser menor a veinte años.

Respecto de la sentencia de segunda instancia, fue recurrida ante la Corte Suprema, máximo tribunal del país, el que no solo confirmó lo ya resuelto por los tribunales de instancia, sino que además reconoció la obligación de resarcir los perjuicios generados.

\subsection{Yacimiento arqueológico El Olivar}

El Olivar fue un asentamiento y necrópolis prehispánica, que actualmente es uno de los yacimientos arqueológicos más importantes de Chile y Sudamérica. Su antigüedad tiene una datación de más de 1.200 años, reuniendo vestigios de varios pueblos prehispánicos, así como la cultura Molle, Animas, Diaguita e Inca. Se ubica a 2 kilómetros hacia el este de la línea de la costa y entre 2 y 4 kilómetros al norte de la ciudad de La Serena, en el sector denominado de las Compañías.

Los antecedentes e investigaciones sobre este importante patrimonio se remontan al siglo XIX, José Toribio Medina, en su obra “Los aborígenes de Chile” (1882). Mas tarde Samuel K. Lathrop excavó 63 sepulturas. El trabajo patrocinado por el Museum of the American Indian, Heye Fundation de Nueva York, nunca se publicó. Con posterioridad Mary Sheperd Slusser, en 1950 elaboró su tesis doctoral sobre este sitio arqueológico, basada en los exhaustivos diarios de campo de Samuel K. Lathrop. 
Francisco Cornely en diversas excavaciones (1936, 1951, 1956), recobró un gran número de objetos, los que en su mayoría fueron depositados en el Museo Arqueológico de La Serena. ${ }^{19}$

En el año 2015, este yacimiento fue descubierto durante la ampliación de la Ruta 5 Norte, cuyo llamado a licitación por el Ministerio de Obras Publicas el año 2013, se adjudicó la empresa española Sacyr. Al comenzar las obras unos 4 kilómetros al norte de La Serena se encontraron una serie de esqueletos, a los que se realizaron algunas pruebas que arrojaron que se trataba de vestigios arqueológicos de larga data.

El Consejo de Monumentos Nacionales, en virtud de la Ley $\mathrm{N}^{\circ} 17.288$, ordenó a la empresa Sacyr realizar una caracterización arqueológica, por lo que la empresa contrató a mediados del 2015 a un equipo de Arqueólogos encabezados por Paola González y Gabriel Cantarutti, quienes realizaron la excavación de 452 pozos de sondeo, no obstante, lo anterior, han transcurrido 3 años desde que este proceso se inició, y la empresa Sacyr se ha negado a realizar el rescate patrimonial.

\section{DESAFÍOS DE LA LEGISLACIÓN NACIONAL}

El 21 de julio de 2016, La Comisión Económica para América Latina y el Caribe y la Organización para la Cooperación y el Desarrollo Económicos ${ }^{20}$, en el contexto de la segunda evaluación de desempeño ambiental de Chile, que contenía 54 recomendaciones, con temas relativos a las políticas de cambio climático, diversidad biológica, recursos hídricos, así como el fomento de una economía más verde y la institucionalidad ambiental.

Chile es una de las economías de la OCDE que realiza un uso más intensivo de los recursos naturales, por lo que el desafío consiste en mantener el progreso económico, y al mismo tiempo brindar protección a sus activos ambientales.

El antecedente a este informe lo encontramos en la primera evaluación realizada en el año 2005, que tuvo como resultado la creación del Ministerio del Medio Ambiente, los tribunales Ambientales y el Servicio de Evaluación Ambiental, entre otras medidas.

Las recomendaciones para la legislación nacional, con relación a la gobernanza y gestión ambiental son:

a.- El desarrollo e implementación de una política de reglamentación de emisiones de contaminantes del agua y del aire de fuentes fijas.

b.- Perfeccionar procesos de evaluación de impacto ambiental, con énfasis en proyectos alternativos, participación ciudadana, y atención a efectos ambientales potenciales.

c.- Mejorar aplicación del Sistema de Evaluación de Impacto Ambiental, especialmente medidas de mitigación y planificación de construcción de viviendas e infraestructura, desde planes reguladores comunales. Ambiente.

d.- Fortalecer políticas de cumplimiento y fiscalización de la Superintendencia del Medio

e.- Establecer un estricto régimen de responsabilidad por el daño futuro, así como la implementación de normas y planes de rehabilitación. Facultar al Servicio del Medio Ambiente para que haga cumplir las disposiciones sobre responsabilidad mediante medidas administrativas.

Por otra parte, las recomendaciones apuntan hacia un crecimiento verde. En el año 2014 se aprobó una reforma tributaria que buscaba disminuir brecha fiscal, y establecer un sistema tributario más progresivo, así como reducir la desigualdad de ingresos, lo que la reforma no ha logrado por importantes inconsistencias técnicas y prácticas. No obstante, lo anterior, se incluyeron impuestos ambientales, como por ejemplo el impuesto a los vehículos livianos, desincentivando la compra de vehículos que generen mayores emisiones.

19 GONZALEZ PAOLA, Sitio El Olivar: su importancia para la reconstrucción de la prehistoria de las comunidades agroalfareras del norte semiárido chileno. Colecciones Digitales, Subdirección de Investigación Dibam.

${ }^{20}$ Comisión Económica para América Latina y el Caribe (CEPAL)/Organización para la Cooperación y el Desarrollo Económicos (OCDE), Evaluaciones del desempeño ambiental: Chile 2016, Santiago, 2016. 
Las grandes fuentes fijas también deberán pagar impuestos sobre las emisiones de contaminantes locales y de dióxido de carbono. Este gravamen es una innovación muy importante, ya que los impuestos ambientales representaron durante 2014 el 1,2\% del PIB, que representa uno de los porcentajes más bajos de todos los países de la OCDE.

Por otra parte, el gasto destinado a protección ambiental constituye una importante partida del presupuesto de la nación, el que ha experimentado un aumento del $178 \%$ entre los años 2000 y 2014. Además, el Gobierno de Chile, durante el año 2015 dio a conocer un estudio general sobre el gasto público en la protección del medio ambiente, el que ha manifestado un importante avance.

Las recomendaciones sobre el crecimiento verde son, entre otras:

a.- Elevar tasa impositiva de gasolina y diésel.

b.- Evaluar mecanismo de estabilización de precios de los combustibles

c.- Revisar impuestos sobre las emisiones de contaminantes atmosféricos locales y CO2 de grandes fuentes fijas.

d.- Impuestos sobre los vehículos.

En relación con la conservación y el uso sostenible de la diversidad biológica, las recomendaciones y desafíos son:

a.- Aprobar proyecto de ley que crea el Servicio de Diversidad Biológica y Áreas Protegidas.

b.- Reformas institucionales y normativas para implementar sistema de gestión integrada de cuencas hidrográficas.

c.- Perfeccionar participación de organizaciones no gubernamentales, gobiernos locales y las comunidades indígenas.

d.- Desarrollo y actualización de planes de gestión de todas las áreas protegidas.

Los recursos naturales son un pilar clave de la economía chilena y su desarrollo. El ser productor mundial de cobre, exportador de productos agrícolas, forestales y pesqueros, así como el sostenido desarrollo de la actividad turística, han permitido que en las últimas décadas el país haya mejorado sostenidamente los niveles de vida de la población, lo que exige y plantea grandes desafíos para la protección del patrimonio y los recursos naturales, así como la necesidad de desarrollar una sólida institucionalidad que otorgue efectiva protección a estos bienes jurídicos.

La participación de múltiples actores dentro de la actividad turística obliga a la existencia de una cooperación entre ellos, y es en ese sentido que las empresas que desarrollan y fomentan el crecimiento de esta actividad deban tener un compromiso con el cuidado del entorno en que se ejecuta, de tal modo, tiene plena aplicación el concepto de responsabilidad social empresarial, que se ha conceptualizado como: "un corpus que explica y sustenta una perspectiva ética en las prácticas empresariales. Este cambio de paradigma se ha impulsado desde los agentes sociales interactuantes con la empresa y también desde diversas instituciones internacionales que han visto con buenos ojos la promoción de una cultura empresarial con sentido social. Varios organismos internacionales públicos como la Organización de Naciones Unidas (ONU), la Unión Europea (UE) y la Organización para la Cooperación y el Desarrollo (OCDE) han propuesto directrices respecto a la responsabilidad social de las empresas con el fin de promover una economía más competitiva y dinámica en relación con la generación de mejores empleos y mayor cohesión social en el mercado." 21

La importancia de este concepto se ve reflejada en la intervención de diversos órganos internacionales en su delimitación y promoción, siendo a nuestro entender un desafío no solamente legislativo, sino que también cultural, entendiendo que el medio de soporte de la actividad turística es susceptible de ser dañado a través de su ejercicio, por lo que una explotación responsable de los recursos disminuirá la posibilidad de producción de daños.

21 WOJTAROWSKI LEAL, SILVA RIVERA, PINAR ÁLVAREZ y NEGRETE RAMÍREZ. La Responsabilidad Social Empresarial como pieza clave en latransición hacia el desarrollo sustentable en el sector turístico. En: Pasos, Revista de Turismo y Patrimonio Cultural, 2016, Vol. 14 Nº1 pp. 127-139. 
Desde el punto de vista de la atribución de responsabilidad del causante de un daño ambiental, destacamos que en Chile existe un sistema de imputación subjetivo, es decir, la víctima debe demostrar la existencia de culpa o dolo por parte del autor del hecho u omisión dañosa. A pesar de que ese criterio se ajusta al principio de la realidad, en que corresponde acreditar los hechos a quien los afirma, en estos casos particulares existe una clara dificultad para determinar esas circunstancias con medios probatorios, sobre todo cuando nos encontremos ante cursos causales múltiples o que por la posible desviación causal pueden generar una barrera de entrada a la acción indemnizatoria. La tendencia a nivel mundial es generar estatutos objetivos que produzcan una inversión de las cargas probatorias, reconociendo las dificultades en que una parte puede encontrarse.

\section{CONCLUSIÓN}

La relación existente entre patrimonio ambiental y patrimonio turístico es tan estrecha que muchas veces las normativas aplicables convergen entre sí, generando una relación que permite una cierta flexibilidad en la resolución de conflictos relacionados. Pero es necesario considerar el explosivo aumento que ha tenido la actividad turística en nuestro país, ya que las normas e instituciones que se crearon, lo hicieron bajo otra realidad.

En la actualidad, nos encontramos ante normativas que pueden ser poco específicas y que entregan una protección limitada en atención a las múltiples circunstancias que pueden presentarse. La generación de estatutos especiales no es una solución fácil, requiere la conciliación de muchos factores diversos, pero creemos que una actualización se encuentra justificada a la orden de modernizar nuestra legislación atendiendo a una nueva realidad y escenario en la actividad turística.

Poner el énfasis en la regulación sancionatoria, pretendiendo que tenga un fin disuasivo es una de las alternativas que puede adoptarse, ya que es necesario que los daños que se produzcan sean efectivamente reparados de manera oportuna pero la sanción implica necesariamente que se ha generado un daño y es ahí donde debe estar el énfasis, esto puesto que la prevención de daños ambientales es la forma de progresar hacia una legislación moderna y armónica. A pesar de que se sancione a un turista infractor y que este sea condenado a la reparación del componente ambiental afectado, nunca podrá recuperarse al estado en que se encontraba, y el equilibrio del medioambiente se verá necesariamente afectado. Las acciones que tienden a su protección están necesariamente vinculadas entre sí.

Junto con ello, los plazos vinculados a las acciones judiciales debe ser otro de los elementos a considerar para poner el acento sobre la prevención como una mejor alternativa para seguir desarrollando una creciente actividad turística. Los juicios de estas características pueden implicar una tramitación superior a los cinco años, sin contar la etapa de la ejecución de la sentencia, por lo que el componente ambiental afectado será reparado, en la medida de lo posible, con una delación temporal demasiado extensa.

Es cierto que la creación de una institucionalidad turística y ambiental ha significado un paso para igualar las directrices que a nivel mundial se han seguido respecto de estas áreas, pero dicha institucionalidad y normas fueron concebidas bajo una realidad turística cuantitativamente inferior, debiendo ser capaces de reconocer estos cambios de manera previa, evitando aprender de las experiencias que siempre significarán una pérdida irreversible de los componentes que forman un atractivo turístico y configuran el patrimonio ambiental.

\section{BIBLIOGRAFÍA}

BARROS BOURIE, Enrique; Tratado de responsabilidad extracontractual. En Santiago, Editorial jurídica, año 2010, pp 61-62. 
BERMUDEZ SOTO, JORGE, Fundamentos del Derecho Ambiental. En Valparaíso, $2^{\mathrm{a}}$ Edición Ediciones Universitarias de Valparaíso, año 2010, p 238.

Comisión Económica para América Latina y el Caribe (CEPAL)/Organización para la Cooperación y el Desarrollo Económicos (OCDE), Evaluaciones del desempeño ambiental: Chile 2016, Santiago.

CONSEJO DE MONUMENTOS NACIONALES DE CHILE, Estadística de Monumentos Nacionales declarados por decreto, 2018. [consulta: 09 de noviembre de 2018]. Disponible en: http://www.monumentos.cl/monumentos/

GONZALEZ CARVAJAL, PAOLA, Sitio El Olivar: su importancia para la reconstrucción de la prehistoria de las comunidades agroalfareras del norte semiárido chileno. En Colecciones Digitales, Subdirección de Investigación Dibam, año 2017.

MATUS ACUÑA, ORELLANA CRUZ, CASTILLO SÁNCHEZ y RAMÍREZ GUZMÁN, Análisis dogmático del derecho penal ambiental chileno, a la luz del derecho comparado y las obligaciones contraídas por chile en el ámbito del derecho internacional. Conclusiones y propuesta legislativa fundada para una nueva protección penal del medio ambiente en Chile, en: Revista Ius et Praxis, 2003, año 9 №2. Pp. 11-57.

NOGUEIRA ALCALA, HUMBERTO, Derechos fundamentales y garantías constitucionales. En Santiago, Editorial Librotecnia, año 2008, p 632.

VALENZUELA FUENZALIDA, RAFAEL, El derecho ambiental presente y pasado. En Santiago, Editorial Jurídica de Chile, año 2010, p238.

WOJTAROWSKI LEAL, SILVA RIVERA, PINAR ÁLVAREZ y NEGRETE RAMÍREZ. La Responsabilidad Social Empresarial como pieza clave en latransición hacia el desarrollo sustentable en el sector turístico. En: Pasos, Revista de Turismo y Patrimonio Cultural, 2016, Vol. 14 No1 pp. 127-139. 